\title{
How to Prevent Young People from Self-Harm
}

\author{
Heon-Jeong Lee ${ }^{1,2}$, Editor-in-Chief \\ ${ }^{1}$ Department of Psychiatry, Korea University College of Medicine, Seoul, Republic of Korea \\ ${ }^{1}$ Chronobiology Institute, Korea University, Seoul, Republic of Korea
}

Nonsuicidal self-injury (NSSI) is a deliberate and repetitive self-harmful act aimed at destroying one's own body. Common NSSI behaviors include cutting, carving skin, burning skin, or deliberate fracture. Sometimes, self-injuries can be easily hidden or regarded as accidents, such as lip biting, falling, or kicking the edge of furniture. NSSI has been increasing rapidly in adolescents and young adults in South Korea in recent years. In 2018, the Korean Ministry of Education conducted a nationwide survey of middle and high school students' emotional and behavioral characteristics. For the question "Have you ever engaged in self-harm?" 4,055 out of 513,710 middle school students (7.9\%) answered they had some experience of self-harm. Next, out of 452,107 high school students, 20,906 (6.4\%) had experienced a lower percentage than middle school students. ${ }^{1}$ Self-harm is spreading like a virus. Social networking services are increasingly showing pictures and videos containing scenes with self-injury. In psychiatric clinics, more cases of self-harm are being reported than in the past. Even if there is no suicide intention, scarring creates cosmetic problems, and repeated self-injuries may lead to serious suicidal behavior. ${ }^{2}$ Therefore, understanding the epidemiology and psychopathology of self-injurious behavior is important for its prevention and treatment.

Thus, the study on validation of the Korean version of the Inventory of Statements about Self-Injury (ISAS) in this issue of Psychiatry Investigation is meaningful for understanding the psychopathology of NSSI in Korean young adults. ${ }^{3}$ The first section of the ISAS measures the lifetime frequency of 12 NSSI behaviors (e.g., burning, cutting, and carving) performed intentionally without suicidal intent. They are scored as 0,1 , 2 , or 3 based on the frequency distribution of each self-injurious behavior. The second section of the ISAS consists of 39 items that assess 13 NSSI functions, such as affect regulation and autonomy, which diverges into two superordinate categories: intrapersonal function and interpersonal function. The second section is rated on a scale from 0 to 2 according to the respondent's experience of NSSI functions. According to the

(a) This is an Open Access article distributed under the terms of the Creative Commons Attribution Non-Commercial License (https://creativecommons.org/licenses/bync/4.0) which permits unrestricted non-commercial use, distribution, and reproduction in any medium, provided the original work is properly cited. study, the frequency of NSSI behavior has a positive correlation with suicidal ideation and a negative correlation with resilience. The study demonstrated good internal consistency and temporal stability of the Korean version of the ISAS.

On the other hand, self-harming behaviors are likely to be craving, so it is necessary to evaluate aspects of behavior addiction. ${ }^{4}$ The fact that self-injury is addictive has been observed and reported in patients. Self-harmful behavioral addiction can be explained using neurobiological or psychological mechanisms. If self-harming behaviors are addictive in some cases, it is reasonable to think that compromised functioning of the brain's motivational systems, including the mesocortical dopamine reward system and the endogenous opioid systems, has occurred. ${ }^{5}$ This is relevant because if some individuals' self-harming behaviors are better conceptualized as an addiction, then treatment approaches can be tailored to this addiction. However, ISAS does not assess addiction aspects in self-injury. Research and practical measures are needed to prevent rapidly spreading self-harming behaviors in our society.

\section{Acknowledgments}

This study was supported by the Korea Health 21 R\&D Project funded by the Ministry of Health \& Welfare, Republic of Korea (HM14C2606) and the National Research Foundation of Korea (2017M3A9F1031220).

\section{ORCID iDs}

Heon-Jeong Lee https://orcid.org/0000-0002-9560-2383

\section{REFERENCES}

1. More than 70,000 middle and high school students experienced selfharm. Available at: http://www.hani.co.kr/arti/society/society_general/869668.html. Accessed March 27, 2019.

2. Wilkinson P, Kelvin R, Roberts C, Dubicka B, Goodyer I. Clinical and psychosocial predictors of suicide attempts and nonsuicidal self-injury in the Adolescent Depression Antidepressants and Psychotherapy Trial (ADAPT). Am J Psychiatry 2011;168:495-501.

3. Kim S, Kim Y, Hur JW. Nonsuicidal self-injury among Korean young adults: a validation of the Korean version of the inventory of statements about self-injury. Psychiatry Investig 2019;16:270-278.

4. Blasco-Fontecilla H, Fernández-Fernández R, Colino L, Fajardo L, Perteguer-Barrio R, de Leon J. The addictive model of self-harming (non-suicidal and suicidal) behavior. Front Psychiatry 2016;7:8.

5. Wise RA, Koob GF. The development and maintenance of drug addiction. Neuropsychopharmacology 2014;39:254-262. 